\title{
Changing places to study short-term effects of air pollution on cardiovascular health: a panel study
}

Hans Scheers ${ }^{1}$, Tim S. Nawrot ${ }^{1,2}$, Benoit Nemery ${ }^{1}$ and Lidia Casas ${ }^{1 *}$

\begin{abstract}
Background: Short-term exposure to ambient air pollution triggers acute cardiovascular events. Here, we evaluate the association of exposure to ambient air pollution with two intermediate cardiovascular endpoints: blood pressure and carotid stiffness.
\end{abstract}

Methods: In a one-year panel study, we included 20 healthy volunteers (10 male-female couples aged 59-75 years) with air pollution and health parameters measured every two months at their region of residence (Leuven, Belgium) and twice during two ten-day periods in two locations, one with higher (Milan, Italy) and one with lower (Vindeln, Sweden) air pollution levels (220 observations). We measured blood pressure, carotid arterial stiffness, personal exposure to $\mathrm{NO}_{2}$, and ambient concentrations of $\mathrm{PM}_{10}, \mathrm{PM}_{2.5}$ and $\mathrm{NO}_{2}$. We used linear mixed models to evaluate the associations between the health outcomes and the air pollutants.

Results: Compared with Leuven, exposure to pollutants was higher in Milan and lower in Vindeln, with the highest contrast for $\mathrm{NO}_{2}$ (median $20.7 \mu \mathrm{g} / \mathrm{m}^{3}$ (IQR:7.4) vs $65.1 \mu \mathrm{g} / \mathrm{m}^{3}$ (9.0) and $4.5 \mathrm{mg} / \mathrm{m}^{3}$ (0.8), respectively). We did not observe significant associations between either systolic or diastolic blood pressure and variations in air pollution. However, we found significant associations between arterial stiffness and 5 day average exposure to the studied pollutants. The strongest associations were observed for $\mathrm{PM}_{10}$ with carotid distensibility (DC) and compliance (CC) coefficients, and the young elastic modulus (YEM): 4.3\% (95\%Cl:7.0;1.5) increase in DC, 4.7\% (95\%Cl:7.1;2.3) increase in CC and 4.2\% (95\% Cl:1.1;7.3) decrease in YEM for each $10 \mu \mathrm{g} / \mathrm{m}^{3}$ decreases in $\mathrm{PM}_{10}$.

Conclusions: Our study suggests that short-term exposure to air pollution results in reductions in carotid elasticity among elderly population.

Keywords: Air pollution, Carotid stiffness, Blood pressure, Quasi-experimental study

\section{Introduction}

Ambient air pollution is an important cause of respiratory and cardiovascular morbidity and mortality $[1,2]$. Overall, 3.7 million deaths and $3.1 \%$ of disability-adjusted life years (DALY) worldwide are attributed to air pollution, placing it in the top 10 of risk factors [3]. It has been abundantly demonstrated that short-term exposure to air pollution (hours to a few days of exposure) can trigger acute events such as myocardial infarctions [4-6], whereas long-term exposure (after several years of exposure) has been linked

\footnotetext{
* Correspondence: lidia.casasruiz@kuleuven.be

${ }^{1}$ Environment and Health Unit, Department of Public Health and Primary

Care, KU Leuven, Herestraat 49, O\&N I, PB 706, 3000 Leuven, Belgium

Full list of author information is available at the end of the article
}

to both the onset of acute events and the development of chronic diseases [7, 8]. In addition to epidemiological research, controlled-exposure studies in animals and humans have provided insight into possible physiological pathways underlying the relationship between inhalation of pollutants and cardiovascular and respiratory health. These pathways have been reviewed recently [9-11].

In this study, we combine the advantages of epidemiological and experimental studies to investigate the associations between air pollution and intermediate cardiovascular health endpoints. To achieve our objective, we deliberately moved a panel of study volunteers from their living area around Leuven, Belgium [yearly average $\mathrm{PM}_{10}$ (particulate matter) around $30 \mu \mathrm{g} / \mathrm{m}^{3}$ ] for several days to locations with

(c) The Author(s). 2018 Open Access This article is distributed under the terms of the Creative Commons Attribution 4.0 International License (http://creativecommons.org/licenses/by/4.0/), which permits unrestricted use, distribution, and 
contrasting levels of air pollution: Milan, Italy $\left(>50 \mu \mathrm{g} / \mathrm{m}^{3}\right)$ and Vindeln, Sweden $\left(<10 \mu \mathrm{g} / \mathrm{m}^{3}\right)$, i.e. locations representative for the highest and lowest levels of PM pollution in Europe, respectively [12-14]. We quantified several healthrelated endpoints that have been identified as intermediate steps between exposure and disease [15-18]. Here, we present the results for the association between air pollution concentrations and blood pressure and carotid stiffness, as intermediate endpoints in the associations between air pollution and cardiovascular diseases.

\section{Methods}

\section{Study design and participants}

We conducted a one year panel study in healthy elderly volunteers and measured multiple health endpoints and exposure to air pollution in locations with differing ambient air pollution levels. We included 10 healthy retired male-female couples with both partners fulfilling the following inclusion criteria: age approximately 60-75 years, never or > 1 year former smokers, good general health, willing and available to travel during the study period, and fluent in Dutch. We excluded persons with mobility problems; a history of cardiovascular disease (except uncomplicated hypertension), cancer, or other diseases that could interfere with the measurements or would represent a risk during travel. All participants were given detailed oral and written information on the study and gave written informed consent. The study was approved by the Ethical Committee of KU Leuven (S55482).

From September 2013 to September 2014, we collected data over 11 measurement time points: seven in Leuven (Belgium), two during a 10-day stay in Milan (trip days 5 or 6 , and 9 or 10), and two during a 10-day stay in Vindeln (trip days 5 or 6 and 9 or 10), a rural area near Umeå, northern Sweden (Fig. 1). To limit differences in temperature between the two trips, we stayed in Milan in October $\left(2013\right.$, average daily temperature $13^{\circ} \mathrm{C}$ ) and in Vindeln in June $\left(2014\right.$, average daily temperature $\left.14^{\circ} \mathrm{C}\right)$ [19]. Environmental data form monitoring stations and personal exposure samplers was collected during each measurement time point and on the four days prior to it. Clinical measurements were performed in adequate study rooms at the Universitair Ziekenhuis Leuven, the
Ospedale Maggiore in Milan, and Umeå University. We collected blood, sputum and urine samples, measured blood pressure, endothelial function and carotid stiffness, the study volunteers underwent cognitive tests and spirometries, their physical activity was measured with accelerometers, and they were administered health questionnaires and diet diaries. To further describe the baseline health status of our study participants we determined (at baseline) plasma levels of cholesterol and glucose in fasted blood samples. Additional information on the study design and population is provided elsewhere [20]. The study presented here focuses on the results for blood pressure and carotid stiffness measurements.

\section{Cardiovascular intermediate endpoints: Blood pressure and carotid stiffness}

Systolic (SBP) and diastolic blood pressure (DBP) were measured according to guidelines of the European Society of Hypertension [21], with an automated device (Stabilograph, Stolberg, Germany). After the subject had rested for at least $10 \mathrm{~min}$, blood pressure was measured five times consecutively in sitting position. We used the average of the last two measurements for analyses, and we calculated pulse pressure $(\triangle \mathrm{P}=\mathrm{SBP}-\mathrm{DBP})$, and mean arterial pressure as $\mathrm{DBP}+\Delta \mathrm{P} / 3$.

Carotid stiffness was measured by using an ultrasound device with automatic boundary detection software in RF-mode (MyLabOne, Esaote Benelux, Maastricht, The Netherlands) according to previously reported protocols [22]. Participants rested for $10 \mathrm{~min}$ in a supine position before starting the measurements. All measurements were performed by the same trained investigator by longitudinal scanning of a $1 \mathrm{~cm}$ segment of the right common carotid artery at $1 \mathrm{~cm}$ proximally to the dilatation of the carotid bulb visualizing the lumen-intima and media-adventitia interfaces of the far arterial wall. Carotid intima-media thickness was determined under three different angles $\left(90^{\circ}, 130^{\circ}\right.$ and $\left.180^{\circ}\right)$.

We averaged diastolic artery diameter and systolic increase in diameter over three consecutive ultrasound measurements, each spanning eight cardiac cycles. We used $\mathrm{D}$ and $\Delta \mathrm{D}$ to calculate four parameters related to arterial stiffness $[23,24]$. Carotid distensibility (DC)

Assessment periods:
Fig. 1 Timeline of the study. All variables mentioned in the text were measured in 20 study volunteers in all 11 periods, except for and plasma
levels of cholesterol and glucose which was only measured at baseline (assessment period 1)


and compliance (CC) coefficients are inversely related to arterial stiffness, and pulse wave velocity (PWV) is a direct measure of arterial stiffness. Young's Elastic Modulus (YEM) combines measures of arterial wall elasticity with intima media thickness. Thus, we expected to observe direct associations with air pollution for PWV and YEM and inverse associations for DC and CC. Intra-observer coefficients of variation ranged from 5.2 to $10.1 \%$ for the different stiffness parameters, indicating good reproducibility of measurements [17].

\section{Air pollutants}

Participants lived within a maximum distance between the residences of $45 \mathrm{~km}$. We estimated their daily average residential exposure to $\mathrm{PM}_{10}, \mathrm{PM}_{2.5}$, and $\mathrm{NO}_{2}$ using interpolated values in 4 by $4 \mathrm{~km}$ grids, based on the Belgian telemetric air quality network [25]. In Milan, daily averages from eight monitoring stations in the city were calculated using the information provided by the online database of the Regional Agency for the Protection of the Environment in Lombardy (ARPA Lombardia: http:// www.arpalombardia.it) [26]. In Vindeln, we averaged daily data from the nearest monitoring stations in Umea, Skellefteå and Strömsund. In addition, we measured personal exposure to $\mathrm{NO}_{2}$ using Radiello diffusive samplers (Sigma-Aldrich, Bellefonte, PA, USA). Depending on the measurement period, six to 19 participants wore the clip-on device during five days prior to each health assessment day in Leuven or to the last health assessment days in Milan and Vindeln. The number of samplers distributed was lower during the trips because all participants stayed at the same hotel and performed group activities during the day. In Belgium, one sampler was provided to each couple. However, to check potential differences in exposure within the couples, we provided 19 samplers in one measurement period. No significant differences were observed within couples. Personal exposure to $\mathrm{NO}_{2}$ was expressed as average concentrations $\left(\mu \mathrm{g} / \mathrm{m}^{3}\right)$ [27]. The quantification of average exposure to $\mathrm{NO}_{2}$ was performed at the lab of the Fondazione Salvatore Maugeri (Padova, Italy).

\section{Potential confounders}

In this study, we included information obtained by face-to-face interviews on smoking status (never or former), medication use for hypertension, and having a cold. Regarding smoking status, our study included 10 former smokers who had stopped smoking 6 to 43 years (average $=29$ years) previous to the start of the study and who smoked 0.6 to 18 packs-year (average $=6.5$ ). In addition, we included heart rate measured with electrocardiogram, and considered physical activity (number of steps measured with an accelerometer) performed during the week previous to the cardiovascular measurements, and alcohol consumption reported on a diet diary for seven days prior to the measurements.

Environmental potential confounders such as daily temperature and relative humidity during the study period were obtained from local meteorological websites for Belgium (http://www.meteobelgie.be) and Milan (www. ilmeteo.it) and an international website for Umeå (http:// www.wunderground.com).

\section{Statistical analysis}

Statistical analyses were performed in SAS 9.4 (SAS Institute, Cary, NC, USA). We investigated associations between health parameters and exposure to air pollution by using linear mixed models with variance components covariance structure, accounting for the repeated-measures design of the study. 'Acute' effects of air pollution were estimated as 5 day effects by calculating the average of lag days 0 to 4 (referred to as 'av04'), where lag 0 is the daily average of pollutant concentrations on the day of the health measurement, lag 1 the day before, lag 2 two days before, lag 3 three days before and lag 4 four days before. Thus, we obtained an average of daily averages of 5 consecutive days including the day of the health measurement and the 4 days prior to them. Personal exposure to $\mathrm{NO}_{2}$ was available as five day average concentrations [27] and included measurements of 4 days prior to the health measurements and of the day of the health measurements but only until the hour of its performance. During the trips, personal exposure to $\mathrm{NO} 2$ was measured only once (during 5 days). In the mixed models we used all repeatedly measured cardiovascular intermediate endpoints and the $\mathrm{NO}_{2}$ exposure, which reflects the average exposure during the trip.

The models were adjusted for age at baseline, sex, date of measurement, ambient temperature, relative humidity, heart rate, having a cold, high blood pressure medication, and smoking status. The models for the carotid stiffness measurements were additionally adjusted for mean arterial pressure. The inclusion of information on physical activity and alcohol consumption in the models did not modify the effect estimates and was, therefore, excluded in the final models. We tested the assumption of normal distribution of the error terms by visual inspection of the Q-Q plots of residuals. For PWV, DC, CC, and YEM, this assumption was only met after $\log 10$-transformation. Therefore, results for these outcomes are presented as \% change and their $95 \%$ confidence intervals $(\mathrm{CI})$, whereas parameter estimates of all other analyses are unit changes (beta coefficients) and their CI.

Travelling results in temporary changes in lifestyle as compared with lifestyle patterns followed at home. For example, it may involve changes in physical activity, time spent outdoors, diet, etc. To explore the potential effect of the trips on our results, we performed sensitivity analyses including only the measurements taken in Belgium. 
In addition, we excluded individuals taking antihypertensive medication because this may attenuate the response to air pollution, and we performed 3-level models including individual and couple as random effects to rule out a potential effect of correlated exposures and risk factors within the couple. Finally, we tested potential effect modification of sex and age by including interactions between the pollutants and these variables in the models.

\section{Results}

All 20 participants completed the study in September 2014, without any dropout or missed measurement time point. Table 1 summarizes the main characteristics of the study population at baseline. Six participants took high blood pressure medication during the whole study period, one male started taking this medication after period L2 (Fig. 1). Five-day average concentrations of $\mathrm{PM}_{10}, \mathrm{PM}_{2.5}$, and $\mathrm{NO}_{2}$ are presented in Table 2. Personal exposure to $\mathrm{NO}_{2}$ was clearly highest in Milan $\left(65 \mu \mathrm{g} / \mathrm{m}^{3}\right)$ and lowest in Vindeln $\left(5 \mu \mathrm{g} / \mathrm{m}^{3}\right)$, with intermediate values for Leuven $\left(21 \mu \mathrm{g} / \mathrm{m}^{3}\right)$. Average concentrations of $\mathrm{PM}_{10}$, $\mathrm{PM}_{2.5}$ and $\mathrm{NO}_{2}$ from monitoring stations were highest in Milan, but no big differences were observed between Leuven and Vindeln.

Table 1 Baseline characteristics of the study participants $(n=20)$

\begin{tabular}{|c|c|}
\hline & Median (range) \\
\hline Age, y & $65(58-76)$ \\
\hline Sex (female) $)^{a}$ & $10(50 \%)$ \\
\hline Body-mass index, $\mathrm{kg} / \mathrm{m}^{2}$ & $24.3(18.9-29.4)$ \\
\hline \multicolumn{2}{|l|}{ Smoking status ${ }^{a}$} \\
\hline Former & $10(50 \%)$ \\
\hline Never & $10(50 \%)$ \\
\hline \multicolumn{2}{|l|}{ Plasma cholesterol, mg/dL } \\
\hline Total & $206(144-282)$ \\
\hline $\mathrm{LDL}$ & $133(57-212)$ \\
\hline Plasma glucose, mg/dL & $99(86-131)$ \\
\hline Medication for hypertension ${ }^{a}$ & $6(30 \%)$ \\
\hline \multicolumn{2}{|l|}{ Blood pressure, mm Hg } \\
\hline Systolic & $132(109-165)$ \\
\hline Diastolic & $80(65-105)$ \\
\hline Pulse pressure & $49(40-68)$ \\
\hline \multicolumn{2}{|l|}{ Carotid stiffness } \\
\hline $\mathrm{PW}, \mathrm{m} / \mathrm{s}$ & $8.64(6.65-20.16)$ \\
\hline $\mathrm{DC}, 10^{-3} / \mathrm{kPa}$ & $0.01(0.00-0.02)$ \\
\hline $\mathrm{CC}, \mathrm{mm}^{2} / \mathrm{kPa}$ & $0.66(0.04-1.66)$ \\
\hline YEM, kPa & $0.77(0.48-2.10)$ \\
\hline
\end{tabular}

The crude associations of air pollution and blood pressure and carotid stiffness can be found in the online supplement (Additional file 1: Table S1) and the adjusted associations are presented in Table 3. After adjustment, arterial blood pressure parameters were not significantly associated with the studied pollutant concentrations. Nevertheless, we detected significant associations between the studied pollutant concentrations and the four measures of arterial stiffness. Five day average concentrations of $\mathrm{PM}_{10}$ and $\mathrm{PM}_{2.5}$ were significantly directly associated with PWV and YEM, and inversely with DC and CC. Five day average concentrations of $\mathrm{NO}_{2}$, both from monitoring stations and personal exposure samplers were inversely associated with CC.

In sensitivity analyses excluding the trips to Milan and Vindeln (Additional file 1: Table S2 in the online supplement), $\mathrm{PM}_{10}$ and $\mathrm{PM}_{2.5}$ were statistically significant directly associated with $\Delta \mathrm{P}$. Regarding carotid stiffness, the exclusion of the trips resulted in additional statistically significant associations of $\mathrm{NO}_{2}$ measured from monitoring stations with PWV, DC and YEM in the hypothesized directions (i.e. direct for PWV and YEM and inverse for DC). However, the associations for personal exposure measures of $\mathrm{NO}_{2}$ lose statistical significance. Additional sensitivity analyses excluding individuals taking blood pressure medication or considering the effect of being a couple did not modify our results and the effect of couple was not statistically significant. Finally, interaction terms for sex and age were not statistically significant.

\section{Discussion}

In a quasi-experimental study where we exposed 20 individuals to the range of ambient pollution levels that can be found in Europe, we found that changes in the vascular wall parameters of the carotid artery parallel exposure to five day average ambient air pollution $\left(\mathrm{PM}_{10}, \mathrm{PM}_{2.5}\right.$, and $\left.\mathrm{NO}_{2}\right)$. This occurred without statistically significant associations with blood pressure measurements when including the trips to locations with extreme air pollution concentrations in Europe. Arterial stiffness and reduced elasticity were consistently associated with higher exposure to ambient air pollution. Young's elastic modulus and pulse wave velocity, both direct measures of stiffness [28], were positively associated with PM, while the distensibility and compliance coefficient, both measures of elasticity [29], were negatively associated with five days exposure contrast to $\mathrm{PM}$ or $\mathrm{NO}_{2}$. This finding is in line with follow-up analyses of the Harvard Six Cities cohort study, showing a reduction in mortality risk in association with a decrease in ambient PM concentration [30, 31]. Our study adds evidence of the potential mechanisms involved in the associations observed between long and short term exposure to air pollution and cardio-vascular events. 
Table 2 Description (mean and standard deviation) of five day average concentrations $\left(\mu \mathrm{g} / \mathrm{m}^{3}\right)$ of PM10, $\mathrm{PM}_{2.5}$ in each measurement time point performed in Leuven (Belgium), Milan (Italy) and Vindeln (Sweden) between September 2013 and September 2014

\begin{tabular}{|c|c|c|c|c|c|c|c|}
\hline \multirow[b]{2}{*}{ Year } & \multirow[b]{2}{*}{ Month } & \multirow[b]{2}{*}{ Location } & \multirow[b]{2}{*}{ Visit name } & \multicolumn{3}{|c|}{ Monitoring stations } & \multirow{2}{*}{$\begin{array}{l}\text { Personal samplers } \\
\mathrm{NO}_{2}\end{array}$} \\
\hline & & & & $\overline{P M_{10}}$ & $\mathrm{PM}_{2.5}$ & $\mathrm{NO}_{2}$ & \\
\hline \multirow[t]{4}{*}{2013} & September & Leuven & L1 & $21.9(4.6)$ & $15.9(5.6)$ & $25.1(6.8)$ & $29.8(5.3)$ \\
\hline & October & Milan & M1 & $35.5(2.6)$ & $31.5(2.6)$ & $54.9(1.6)$ & - \\
\hline & & & $\mathrm{M} 2$ & $28.9(2.1)$ & $19.1(1.5)$ & $46.3(0.9)$ & $63.7(4.7)$ \\
\hline & November & Leuven & L2 & $9.4(0.8)$ & $5.9(0.8)$ & $19.4(4.2)$ & $28.5(8.9)$ \\
\hline \multirow[t]{7}{*}{2014} & January & Leuven & L3 & $15.0(2.5)$ & $11.4(2.2)$ & $26.0(5.2)$ & $21.5(8.1)$ \\
\hline & March & Leuven & L4 & $19.8(4.7)$ & $14.5(5.0)$ & $27.5(8.2)$ & $21.4(6.0)$ \\
\hline & May & Leuven & L5 & $13.9(2.0)$ & $7.1(2.4)$ & $16.9(6.3)$ & $16.8(5.0)$ \\
\hline & June & Vindeln & S1 & $19.0(0.5)$ & $6.0(0.4)$ & $19.2(1.0)$ & - \\
\hline & & & S2 & $15.4(0.8)$ & $6.4(0.6)$ & $11.2(0.3)$ & $4.4(0.4)$ \\
\hline & July & Leuven & L6 & $13.8(1.4)$ & $6.9(1.0)$ & $16.9(3.9)$ & $16.3(3.8)$ \\
\hline & September & Leuven & L7 & $22.1(3.7)$ & $15.9(3.2)$ & $22.8(6.0)$ & $19.1(5.9)$ \\
\hline
\end{tabular}

Our results regarding arterial stiffness are in line with results from previous studies [17, 32-34]. Arterial stiffness is an important determinant of increased blood pressure and pulse pressure, and therefore a risk factor of events such as myocardial infarction and stroke $[23,35,36]$. Thus, our results provide a plausible biological mechanism for the demonstrated trigger effect of air pollution on myocardial infarction and stroke [1, 2, 5, 37]. However, the mechanisms responsible for the increase in stiffness by air pollution remain unknown. A proposed mechanism is an increase in inflammation and changes in cardiac autonomic function [9]. Also, diesel exhaust may enhance NO generation, altering the balance of basal generation and consumption of NO and resulting in low NO bioavailability, which would contribute to the cardiovascular effects of air pollution [38].
Regarding blood pressure, short-term or sub-acute (i.e. one week or less) exposure to high concentrations of air pollutants is associated with increases in systolic blood pressure and pulse pressure in healthy elderly, adults and children [39-43]. A recent panel study performed in Michigan (US) and Beijing (China) showed significant effects of sub-acute exposure to air pollution on blood pressure only in Beijing, suggesting that the effect of air pollution in normotensive healthy adults may only be evident in highly polluted areas [44]. In our study, we did not find statistically significant associations between blood pressure measurements and air pollution in the main analyses including all measurement time points. However, we did observe statistically significant direct associations for systolic blood pressure and pulse pressure when excluding the measurements performed during the

Table 3 Adjusted $^{\mathrm{a}}$ changes $(95 \% \mathrm{Cl}$ ) in blood pressure and measures of arterial stiffness associated with an increase in five-day averages of $\mathrm{PM}_{10}, \mathrm{PM}_{2.5}$, or $\mathrm{NO}_{2}$ concentrations (n observations $=220$ )

\begin{tabular}{|c|c|c|c|c|}
\hline & \multicolumn{3}{|l|}{ Monitoring stations } & \multirow{2}{*}{$\begin{array}{l}\text { Personal exposure } \\
\mathrm{NO}_{2} \\
\text { per } 10 \mu \mathrm{g} / \mathrm{m}^{3}\end{array}$} \\
\hline & $\begin{array}{l}\mathrm{PM}_{10} \\
\text { per } 10 \mu \mathrm{g} / \mathrm{m}^{3}\end{array}$ & $\begin{array}{l}\mathrm{PM}_{2.5} \\
\text { per } 5 \mu \mathrm{g} / \mathrm{m}^{3}\end{array}$ & $\begin{array}{l}\mathrm{NO}_{2} \\
\text { per } 10 \mu \mathrm{g} / \mathrm{m}^{3}\end{array}$ & \\
\hline \multicolumn{5}{|l|}{ Blood pressure (unit change) } \\
\hline Systolic, mm Hg & $-0.01(-2.16 ; 2.15)$ & $0.26(-0.72 ; 1.24)$ & $-0.98(-2.23 ; 0.26)$ & $-0.14(-1.17 ; 0.88)$ \\
\hline Diastolic, mm Hg & $-1.14(-2.59 ; 0.30)$ & $-0.28(-0.94 ; 0.38)$ & $-0.66(-1.52 ; 0.19)$ & $-0.28(-1.00 ; 0.43)$ \\
\hline Pulse pressure, mm Hg & $1.11(-0.43 ; 2.65)$ & $0.53(-0.17 ; 1.22)$ & $-0.35(-1.24 ; 0.54)$ & $0.11(-0.62 ; 0.83)$ \\
\hline \multicolumn{5}{|l|}{ Carotid stiffness (\% change) $)^{b}$} \\
\hline $\mathrm{PW}, \mathrm{m} / \mathrm{s}$ & $2.13(0.80 ; 3.47)$ & $0.96(0.32 ; 1.59)$ & $0.78(-0.05 ; 1.61)$ & $0.63(-0.04 ; 1.30)$ \\
\hline $\mathrm{DC}, 10^{-3} / \mathrm{kPa}$ & $-4.25(-6.99 ;-1.51)$ & $-1.91(-3.21 ;-0.61)$ & $-1.58(-3.28 ; 0.12)$ & $-1.31(-2.69 ; 0.07)$ \\
\hline $\mathrm{CC}, \mathrm{mm}^{2} / \mathrm{kPa}$ & $-4.65(-7.05 ;-2.26)$ & $-2.06(-3.20 ;-0.91)$ & $-2.05(-3.54 ;-0.56)$ & $-1.42(-2.64 ;-0.20)$ \\
\hline YEM, kPa & $4.18(1.10 ; 7.25)$ & $2.07(0.60 ; 3.53)$ & $1.56(-0.34 ; 3.45)$ & $1.36(-0.14 ; 2.86)$ \\
\hline
\end{tabular}

${ }^{a}$ Adjusted for age at baseline, sex, heart rate, smoking status, having a cold, medication use for blood pressure, date, temperature, relative humidity

${ }^{\mathrm{b}}$ Models additionally adjusted for arterial pressure

Bold indicates $p$-value $<0.05$

PWV Pulse wave velocity, DC Distensibility coefficient, CC Compliance coefficient, YEM Young's elastic modulus 
trips. Therefore, it is possible that factors related with travelling have affected our results.

A 10-day group travel abroad is very different from the common home situation in many aspects and, although it allowed us to expose our volunteers to a wider range of pollutant concentrations, the trips themselves may also be considered as a limitation of our study. For example dietary changes such as switching to a "Mediterranean diet" in Milan could have attenuated effects of air pollution on blood pressure. In addition, it is possible that the stress of daily duties performed at home (e.g. taking care of grand children) disappeared during the trips. Other factors related to trips may include differences in alcohol consumption, or the amount of physical activity. Nevertheless, including the number of steps and alcohol consumption in our models or excluding the trips in the models for the measures of carotid stiffness did modify our results.

Another limitation of our study was the range of concentrations of air pollutants. We selected the study locations based on their annual PM averages. We expected to find ambient $\mathrm{PM}_{10}$ concentrations as low as $10 \mu \mathrm{g} / \mathrm{m}^{3}$ in rural Sweden and as high as $50 \mu \mathrm{g} / \mathrm{m}^{3}$ in Milan during several days in a row $[12,45]$. However, PM concentrations during the study proved higher than expected in Vindeln $\left(19.8 \mu \mathrm{g} / \mathrm{m}^{3}\right)$ and lower than expected in Milan $\left(30.6 \mu \mathrm{g} / \mathrm{m}^{3}\right)$. Nevertheless, differences between locations were substantial for $\mathrm{NO}_{2}$. This may be explained by the fact that $\mathrm{NO}_{2}$ is more representative of traffic-related pollutants with larger spatial variation in ambient concentration than PM [46]. In addition, our 5-day average concentrations for data acquired from monitoring stations includes daily average concentrations on the day of the health measurements (lag0). This means that $\mathrm{PM}$ and $\mathrm{NO}_{2}$ data obtained from stations include pollution measured after the health measurement. Nevertheless, because we used 5-day average concentrations, the number of hours of pollutant measurements included after the health measurement is small and, therefore, unlikely to have biased our results. Moreover, the results for $\mathrm{NO}_{2}$ from monitoring stations are consistent with those obtained by personal sampling (which was stopped when starting the health measurement).

Nonetheless, our study counts on several strengths. It is a quasi-experimental longitudinal study with 11 measurement time points during one year and a relatively controlled exposure as compared with pure observational studies. During this period, we did not have any drop-out or important change in health status. Moreover, we used a large battery of objective health and exposure measurements, including personal exposure measures of $\mathrm{NO}_{2}$. The number of measurements included strongly increased the statistical power and the use of objective measurements reduced the potential for bias, allowing us to find subtle changes in cardiovascular health parameters related to air pollution.

\section{Conclusions}

From a public health perspective, the findings presented here are relevant. Although the effects found on carotid arterial stiffness are small, previous studies reported that arterial stiffness predicts progression to hypertension in normotensive individuals [47-49]. Ambient air pollution is ubiquitous and the whole population is exposed, including more susceptible subgroups such as children, patients with pre-existing diseases, and elderly [50]. Consequently, small individual risks result in a large global burden [6]. Moreover, the time window of exposure in our study was relatively short, and people living in urban environments are continuously exposed to much higher levels of air pollution (http://www.who.int/phe/health_topics/ outdoorair/databases/cities/en/). In our study, we found that decreases in air pollution exposure were associated with reduced arterial stiffness and improved elasticity. These observations demonstrate that measures leading to a reduction in exposure to air pollution are likely to have beneficial public health effects. In conclusion, our quasi-experimental study shows evidence for subacute effects of exposure to $\mathrm{PM}$ and $\mathrm{NO}_{2}$ on carotid stiffness. In this population age group, exposure to high concentrations of ambient pollutants within 5 days resulted in reduced elasticity of the common carotid artery.

\section{Additional file}

Additional file 1: Table S1. Crude changes $(95 \% \mathrm{Cl})$ in blood pressure and measures of arterial stiffness associated with an increase in five-day averages of PM10, PM2.5, or NO2 concentrations ( $\mathrm{n}$ observations $=220$ ). Table S2. Adjusted changes $(95 \% \mathrm{Cl})$ in blood pressure and measures of arterial stiffness associated with an increase in five day average concentrations of PM10, PM2.5, or NO2 including only measurements performed in Leuven (Belgium) (n observations $=140)$. (DOCX $25 \mathrm{~kb})$

\section{Abbreviations}

CC: Compliance coefficient; Cl: 95\% confidence interval; DALY: Disability-adjusted life years; DBP: Diastolic blood pressure; DC: Distensibility coefficient; PM: Particulate matter; PWV: Pulse wave velocity; SBP: Systolic blood pressure; YEM: Young elastic modulus; $\triangle \mathrm{P}$ : Pulse pressure

\section{Acknowledgements}

We thank the people from the Centrum Klinische Farmacologie at the UZ Leuven for the smooth cooperation. We are grateful to Francesco Blasi and Letizia Morlacchi from the IRCCS Fondazione Ospedale Maggiore in Milan, and to Bertil Forsberg and Helen Bertilsson from Umeå University for their hospitality, providing accommodation for the clinical measurements and all practical help. Nurses Mieke Van Born and Rita Vroom were also a great help during the international parts of the study.

\section{Funding}

This study was supported by the Funding for Scientific Research (FWO-Vlaanderen) (research project nr. G.0165.03). The MyLabOne, Esaote ultrasound device for arterial stiffness was covered by a grant from the European Research Council (ERC-2012-StG 310898). Lidia Casas is recipient of a FWO post-doctoral fellowship.

Availability of data and materials

The datasets used and/or analysed during the current study are available from the corresponding author on reasonable request. 


\section{Authors' contributions}

HS participated in the study design and the data collection, performed the statistical analyses and drafted the manuscript. TSN and BN were involved in the study design and in the interpretation of the results, and revised the manuscript. LC was involved in the study design, coordinated and conducted the data collection, was involved in the interpretation of the results, drafted parts of the manuscript and reviewed it. All authors read and approved the final manuscript.

\section{Ethics approval and consent to participate}

All participants were given detailed oral and written information on the study and gave written informed consent. The study was approved by the Ethical Committee of KU Leuven (S55482).

\section{Consent for publication}

No individual person's data is included in the manuscript.

\section{Competing interests}

The authors declare that they have no competing interests.

\section{Publisher's Note}

Springer Nature remains neutral with regard to jurisdictional claims in published maps and institutional affiliations.

\section{Author details}

"Environment and Health Unit, Department of Public Health and Primary Care, KU Leuven, Herestraat 49, O\&N I, PB 706, 3000 Leuven, Belgium.

${ }^{2}$ Centre for Environmental Sciences, UHasselt, Diepenbeek, Belgium.

Received: 15 August 2018 Accepted: 9 November 2018

\section{Published online: 19 November 2018}

\section{References}

1. Pope CA 3rd, Dockery DW. Health effects of fine particulate air pollution: lines that connect. J Air Waste Manag Assoc. 2006;56:709-42.

2. Anderson JO, Thundiyil JG, Stolbach A. Clearing the air: a review of the effects of particulate matter air pollution on human health. J Med Toxicol. 2012;8:166-75

3. Lim SS, Vos T, Flaxman AD, Danaei G, Shibuya K, Adair-Rohani H, et al. A comparative risk assessment of burden of disease and injury attributable to 67 risk factors and risk factor clusters in 21 regions, 1990-2010: a systematic analysis for the global burden of disease study 2010. Lancet. 2012;380:2224-60

4. Levy Jl, Hammitt JK, Spengler JD. Estimating the mortality impacts of particulate matter: what can be learned from between-study variability? Environ Health Perspect. 2000;108:109-17.

5. Mustafić H, Jabre P, Caussin C, Murad MH, Escolano S, Tafflet M, et al. Main Air Pollutants and Myocardial Infarction. JAMA. 2012;307:713.

6. Nawrot TS, Perez L, Künzli N, Munters E, Nemery B. Public health importance of triggers of myocardial infarction: a comparative risk assessment. Lancet. 2011;377:732-40.

7. Puett RC, Hart JE, Suh H, Mittleman M, Laden F. Particulate matter exposures, mortality, and cardiovascular disease in the health professionals follow-up study. Environ Health Perspect. 2011;119:1130-5.

8. Beelen R, Stafoggia M, Raaschou-Nielsen O, Andersen ZJ, Xun WW, Katsouyanni $\mathrm{K}$, et al. Long-term exposure to air pollution and cardiovascular mortality: an analysis of 22 European cohorts. Epidemiology. 2014;25:368-78.

9. Brook RD, Rajagopalan S, Pope CA 3rd, Brook JR, Bhatnagar A, Diez-Roux AV, et al. Particulate matter air pollution and cardiovascular disease: an update to the scientific statement from the American Heart Association. Circulation. 2010;121:2331-78.

10. Mills NL, Donaldson K, Hadoke PW, Boon NA, MacNee W, Cassee FR, et al. Adverse cardiovascular effects of air pollution. Nat Clin Pr Cardiovasc Med. 2009;6:36-44.

11. Newby DE, Mannucci PM, Tell GS, Baccarelli AA, Brook RD, Donaldson K, et al. Expert position paper on air pollution and cardiovascular disease. Eur. Heart J. 2015:36:83-93.

12. Beelen R, Hoek G, Pebesma E, Vienneau D, de Hoogh K, Briggs DJ. Mapping of background air pollution at a fine spatial scale across the European Union. Sci Total Environ. 2009;407:1852-67.

13. Agency EE. Air quality in Europe - 2015 report. Copenhagen: European Environment Agency; 2015
14. Samoli E, Stafoggia M, Rodopoulou S, Ostro B, Declercq C, Alessandrini E, et al. Associations between fine and coarse particles and mortality in Mediterranean cities: results from the MED-PARTICLES project. Environ Health Perspect. 2013;121:932-8.

15. Brook RD, Urch B, Dvonch JT, Bard RL, Speck M, Keeler G, et al. Insights into the mechanisms and mediators of the effects of air pollution exposure on blood pressure and vascular function in healthy humans. Hypertension. 2009;54:659-67.

16. Briet M, Collin C, Laurent S, Tan A, Azizi M, Agharazii M, et al. Endothelial function and chronic exposure to air pollution in normal male subjects. Hypertension. 2007;50:970-6.

17. Provost EB, Louwies T, Cox B, Op't Roodt J, Solmi F, Dons E, et al. Short-term fluctuations in personal black carbon exposure are associated with rapid changes in carotid arterial stiffening. Environ Int. 2016;88:228-34.

18. Pope CA, Hansen ML, Long RW, Nielsen KR, Eatough NL, Wilson WE, et al. Ambient particulate air pollution, heart rate variability, and blood markers of inflammation in a panel of elderly subjects. Environ Health Perspect. 2003; 112:339-45

19. ClimaTemps.com. World Climate and Temperature. http://www.climatemps. com/. 2015. p. -

20. Bai Y, Casas L, Scheers H, Nemery B, Nawrot TS. Mitochondrial DNA content in blood and carbon load in airway macrophages. A panel study in elderly subjects. Environ. Int. 2018. https://doi.org/10.1016/j.envint.2018.06.003 Accepted.

21. Parati G, Stergiou GS, Asmar R, Bilo G, de Leeuw P, Imai Y, et al. European Society of Hypertension guidelines for blood pressure monitoring at home: a summary report of the second international consensus conference on home blood pressure monitoring. J Hypertens. 2008;26:1505-26.

22. Stein JH, Korcarz CE, Hurst RT, Lonn E, Kendall CB, Mohler ER, et al. Use of Carotid Ultrasound to Identify Subclinical Vascular Disease and Evaluate Cardiovascular Disease Risk: A Consensus Statement from the American Society of Echocardiography Carotid Intima-Media Thickness Task Force Endorsed by the Society for Vascular. J. Am. Soc. Echocardiogr. 2008:93-111. https://doi.org/10.1016/j.echo.2007.11.011.

23. O'Rourke MF, Staessen JA, Vlachopoulos C, Duprez D, Plante GE. Clinical applications of arterial stiffness; definitions and reference values. Am. J. Hypertens. 2002;15(5):426-44.

24. Selzer RH, Mack WJ, Lee PL, Kwong-Fu H, Hodis HN. Improved common carotid elasticity and intima-media thickness measurements from computer analysis of sequential ultrasound frames. Atherosclerosis. 2001:154:185-93.

25. Janssen S, Dumont G, Fierens F, Mensink C. Spatial interpolation of air pollution measurements using CORINE land cover data. Atmos Environ. 2008:42:4884-903.

26. Lombardia A. Daily averages of PM10, PM2.5, BC and NO2 from the netwerk of air pollution monitor stations in Lombardia. 2016. http://www. arpalombardia.it. p. -

27. Gerboles M, Detimmerman F, Amantini L, De Saeger E. Validation of Radiello diffusive sampler for monitoring NO2 in ambient air. Commission of the European Communities; 2000.

28. Urbina EM, Kimball TR, McCoy CE, Khoury PR, Daniels SR, Dolan LM. Youth with obesity and obesity-related type 2 diabetes mellitus demonstrate abnormalities in carotid structure and function. Circulation. 2009;119:2913-9.

29. van der Heiiden-Spek JJ, Staessen JA, Fagard RH, Hoeks AP, Boudier HA, van Bortel LM. Effect of age on brachial artery wall properties differs from the aorta and is gender dependent: a population study. Hypertension. 2000;35:637-42.

30. Laden F, Schwartz J, Speizer FE, Dockery DW. Reduction in fine particulate air pollution and mortality: extended follow-up of the Harvard six cities study. Am J Respir Crit Care Med. 2006;173:667-72.

31. Lepeule J, Laden F, Dockery D, Schwartz J. Chronic exposure to fine particles and mortality: an extended follow-up of the Harvard six cities study from 1974 to 2009. Environ Health Perspect. 2012;120:965-70.

32. Lundback M, Mills NL, Lucking A, Barath S, Donaldson K, Newby DE, et al. Experimental exposure to diesel exhaust increases arterial stiffness in man. Part Fibre.Toxicol. 2009:7. https://doi.org/10.1186/1743-8977-6-7.

33. Unosson J, Blomberg A, Sandstrom T, Muala A, Boman C, Nystrom R, et al. Exposure to wood smoke increases arterial stiffness and decreases heart rate variability in humans. Part Fibre.Toxicol. 2013:20. https://doi.org/10. 1186/1743-8977-10-20

34. Adamopoulos D, Vyssoulis G, Karpanou E, Kyvelou S-M, Argacha J-F, Cokkinos D, et al. Environmental determinants of blood pressure, arterial stiffness, and central hemodynamics. J Hypertens. 2010;28:903-9. 
35. Cecelja M, Chowienczyk P. Role of arterial stiffness in cardiovascular disease. JRSM.Cardiovasc.Dis. 2012. https://doi.org/10.1258/cvd.2012.012016.

36. Vlachopoulos C, Aznaouridis K, Stefanadis C. Prediction of cardiovascular events and all-cause mortality with arterial stiffness. A systematic review and meta-analysis. J. Am. Coll. Cardiol. 2010;55:1318-27.

37. Ljungman PL, Mittleman MA. Ambient air pollution and stroke. Stroke. 2014: 3734-41. https://doi.org/10.1161/STROKEAHA.114.003130.

38. Langrish JP, Unosson J, Bosson J, Barath S, Muala A, Blackwell S, et al. Altered nitric oxide bioavailability contributes to diesel exhaust inhalation-induced cardiovascular dysfunction in man. J Am Heart Assoc. 2013;2:e004309.

39. Liang R, Zhang B, Zhao X, Ruan Y, Lian H, Fan Z. Effect of exposure to PM2.5 on blood pressure. J. Hypertension. 2014;32:2130-41.

40. Tsai D-H, Guessous I, Riediker M, Paccaud F, Gaspoz J-M, Theler J-M, et al. Short-term effects of particulate matters on pulse pressure in two general population studies. J Hypertens. 2015;33:1144-52.

41. Sughis M, Nawrot TS, Ihsan-ul-Haque S, Amjad A, Nemery B. Blood pressure and particulate air pollution in schoolchildren of Lahore. Pakistan BMC Public Health. 2012;12:378.

42. Cai Y, Zhang B, Ke W, Feng B, Lin H, Xiao J, et al. Associations of Short-Term and Long-Term Exposure to Ambient Air Pollutants With Hypertension: A Systematic Review and Meta-Analysis. Hypertens. 2016;68:62-70. https://doi. org/10.1161/HYPERTENSIONAHA.116.07218 (Dallas, Tex. 1979). American Heart Association, Inc.

43. Jacobs L, Buczynska A, Walgraeve C, Delcloo A, Potgieter-Vermaak S, Van Grieken $\mathrm{R}$, et al. Acute changes in pulse pressure in relation to constituents of particulate air pollution in elderly persons. Environ Res. 2012. https://doi. org/10.1016/j.envres.2012.05.003.

44. Huang W, Wang L, Li J, Liu M, Xu H, Liu S, et al. Short-term blood pressure responses to ambient fine particulate matter exposures at the extremes of global air pollution concentrations. Am J Hypertens. 2018;31:590-9.

45. EEA. Air quality in Europe - 2015 report. Copenhagen; 2015.

46. Lewné M, Cyrys J, Meliefste K, Hoek G, Brauer M, Fischer P, et al. Spatial variation in nitrogen dioxide in three European areas. Sci Total Environ. 2004;332:217-30

47. Liao D, Arnett DK, Tyroler HA, Riley WA, Chambless LE, Szklo M, et al. Arteria stiffness and the development of hypertension. The ARIC study. Hypertens. 1999:34:201-6 (Dallas, Tex. 1979).

48. Arnett DK, Glasser SP, McVeigh G, Prineas R, Finklestein S, Donahue R, et al. Blood pressure and arterial compliance in young adults: the Minnesota Children's blood pressure study. Am J Hypertens. 2001;14:200-5.

49. Femia R, Kozakova M, Nannipieri M, Gonzales-Villalpando C, Stern MP, Haffner SM, et al. Carotid intima-media thickness in confirmed prehypertensive subjects: predictors and progression. Arterioscler Thromb Vasc Biol. 2007:27:2244-9.

50. Sacks JD, Stanek LW, Luben TJ, Johns DO, Buckley BJ, Brown JS, et al. Particulate matter-induced health effects: Who is susceptible? Environ. Health Perspect. 2011:446-54. https://doi.org/10.1289/ehp.1002255.

Ready to submit your research? Choose BMC and benefit from:

- fast, convenient online submission

- thorough peer review by experienced researchers in your field

- rapid publication on acceptance

- support for research data, including large and complex data types

- gold Open Access which fosters wider collaboration and increased citations

- maximum visibility for your research: over $100 \mathrm{M}$ website views per year

At $\mathrm{BMC}$, research is always in progress.

Learn more biomedcentral.com/submissions 